\title{
A Study of Preparation and Performance of the PCMs of the CA-LA Swelling Vitrified Beads

\author{
Li-Guang XIAO ${ }^{1, a}$, Shuang SONG ${ }^{1, b}$, Shi-Zhe GAO ${ }^{1, c}$
}

${ }^{1}$ School of Materials Science and Engineering, Jilin Jianzhu University , Changchun 130118, China

axlg627@163.com, ${ }^{\mathrm{b}} 478048400 @ q q . c o m,{ }^{\circ} 617997628 @ q q . c o m$

Keywords: CA-LA, Swelling Vitrified Beads, Composite Phase Change Materials, Thermoregulation and Energy Saving.

\begin{abstract}
We prepare binary phase change materials by using decanoic acid-lauric acid and use swelling vitrified beads as adsorption carrier, adoptting vacuum adsorption method to prepare composite phase change material. We measure that the phase change temperature and phase change latent heat of different proportions of decanoic acid and lauric acid and that phase change temperature and phase change latent heat of composite phase change materials after adsorption by using DSC. Using scanning electron microscopy (SEM) to characterize the microstructure of composite materials. The results show that: when CA:LA=7:3, phase change latent heat is highest, it reaches $143.48 \mathrm{~J} / \mathrm{g}$, the phase transition temperature is $23.93{ }^{\circ} \mathrm{C}$, endothermic peak area is $659.57 \mathrm{~mJ}$; In composite phase change materials, suitable proportion of phase change materials and the carrier is $1.8: 1$, at this time, the phase transition temperature is $21.73^{\circ} \mathrm{C}$, phase change latent heat of $120.04 \mathrm{~J} / \mathrm{g}$, endothermic peak area is $495.02 \mathrm{~mJ}$.
\end{abstract}

\section{Introduction}

The phase change material is a kind of the new energy-saving material which can take advantage of changes in the natural source of the initiative to achieve the storage and release of energy[1]. The indoor temperature is automatically adjusted by the PCM to achieve the purpose of energy-saving. The micro-capsule technology and the nano-composite technology are generally used as kinds of packaging technology by domestic and foreign which make encapsulate phase change materials into energy microspheres. Thereby the composite stable phase change material is made[3]. It is difficult to achieve large-scale production because of its expensive cost of packaging[4]. In this paper, the PCM is adsorbed to swelling vitrified bead which is a kind of porous material by the adsorption method of packaging. Thus the granular phase change material is made. The compatibility problems of the phase change material and building material are effectively solved by the granular phase change materials, at the same time, the heat transfer performance of entire system is improved[5]. In this study, we use capric acid and lauric acid as the original PCM to study phase change materials and use swelling vitrified beads as a kind of adsorption materials to make composite phase change materials. Finally we study the performance of the composite phase change materials.

\section{Experimental Procedure}

\section{Materials and Properties}

Materials. CA; LA; swelling vitrified beads: Water absorption: 60\%-70\%, Granularity: 0.5-3.5mm, Bulk Density: $80-120 \mathrm{~kg} / \mathrm{m} 2$.

Properties. vacuum pump, ZDHW, water bath, flask, dropping funnel, DSC, SEM and so on.

\section{Experimental Procedure}

Preparation of Phase Change Materials (PCMs). Firstly, a certain amount of capric acid and lauric acid are weighed. Then capric acid is melted in the water bath of the constant temperature and gradually added lauric acid to capric acid. It is continued to stir both capric acid and lauric acid until to mix uniformily. Follow on cooling at room. Finally the phase change material is made. 
Preparation of Inorganic-organic Shaped Composite Phase Change Materials. Firstly, the three-necked flask was placed in a ZDHW of temperature heating $\left(70{ }^{\circ} \mathrm{C}\right)$, and we make a certain amount of swelling vitrified beads which is weighed into the three-necked flask; Then we make a certain amount dissolved phase change material $\left(70^{\circ} \mathrm{C}\right)$ to the dropping funnel; Follow we open the vacuum pump, an agitator (setting an appropriate stirring speed) and slowly drop molten phase change material. Finally the composite phase change material is made.

\section{Results and Discussion}

\section{Results and Discussion of the DSC of the PCMs}

The DSC of the PCMs. The results of the DSC of the different proportions' PCM. In figure 1figure 9 and table 1.
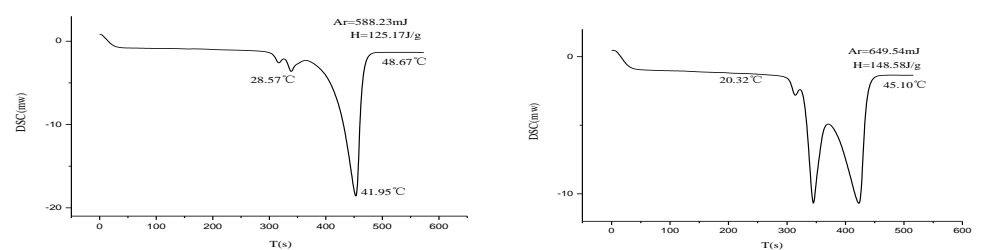

Fig.1The DSC of CA:LA=1:9 Fig.2 The DSC of CA:LA=2:8
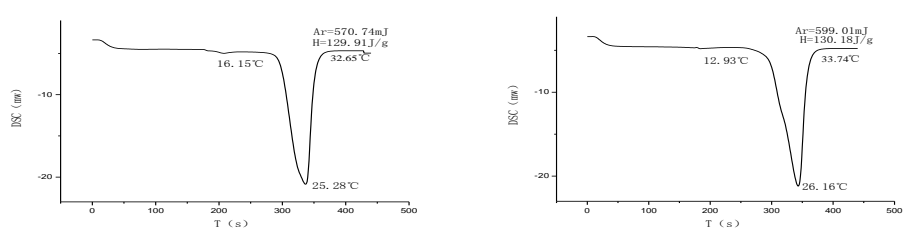

Fig.4 The DSC of CA:LA=4:6
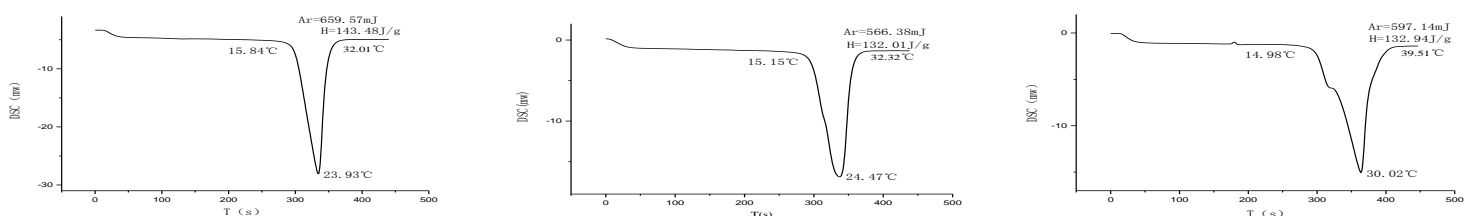

Fig.7 The DSC of CA:LA=7:3 Fig.8 The DSC of CA:LA=8:2 Fig.9 The DSC of CA:LA=9:1

Conclusions. Composite phase change materials which apply in indoor buildings should have high latent heats and a sensible phase transition temperature point. It depends on the different areas of using: The reasonable temperature which applys the southern indoors is $25^{\circ} \mathrm{C}-28^{\circ} \mathrm{C}$ and which applys the north indoors is $18^{\circ} \mathrm{C}-26^{\circ} \mathrm{C}$.In this paper, the PCMs which study and discuss are based on the temperature characteristics of the north room.

Figure1, figure 2 and figure9, their phase-transition temperatures were $41.95^{\circ} \mathrm{C}, 38.26^{\circ} \mathrm{C}$ and $30.02^{\circ} \mathrm{C}$, they have been remotely beyond the body of the appropriate temperature range. We can observe the PCM occurs secondary phase when the phase-transition rises to near $35^{\circ} \mathrm{C}$ from figuer2.Now the capric acid blends $20 \%$.It also can not be applied in practice.Figure 3 , its phase temperature is suitable, but it occurs a phenomenon of phase separation. This PCM would make pollution to the environment if it been applied. Figure4-8,their phase-transition temperatures conform to temperature' $\mathrm{s}$ feature of the northern interior. This PCM has a higher latent heat and dose not occur phase separation. In this range, the PCMs conform to requirement of the actual using. When the capric acid blends $70 \%$, the PCMs' the phase-transition temperature is the most suitable and its heat is highest. now its phase-transition temperature is $23.93^{\circ} \mathrm{C}$, its heat is $143.48 \mathrm{~J} / \mathrm{g}$, its 
endothermic peak area is $659.57 \mathrm{~mJ}$.

Tab.1 The characterization of binary phase transformation system

\begin{tabular}{cccccc}
\hline CA:LA & $\begin{array}{c}\text { The initial } \\
\text { temperature } \\
\left({ }^{\circ} \mathrm{C}\right)\end{array}$ & $\begin{array}{c}\text { final } \\
\text { temperature } \\
\left({ }^{\circ} \mathrm{C}\right)\end{array}$ & $\begin{array}{c}\text { phase-transiti } \\
\text { on } \\
\text { temperature } \\
\left({ }^{\circ} \mathrm{C}\right)\end{array}$ & heat $(\mathrm{J} / \mathrm{g})$ & $\begin{array}{c}\text { Endothermic } \\
\text { peak } \\
\text { area }(\mathrm{mJ})\end{array}$ \\
\hline $1: 9$ & 28.57 & 48.67 & 41.95 & 125.17 & 588.23 \\
$2: 8$ & 20.32 & 45.10 & 38.26 & 148.58 & 649.54 \\
$3: 7$ & 19.67 & 40.08 & 25.58 & 141.84 & 537.69 \\
$4: 6$ & 16.15 & 32.65 & 25.28 & 129.91 & 570.74 \\
$5: 5$ & 12.93 & 33.74 & 26.16 & 130.18 & 599.01 \\
$6: 4$ & 16.67 & 34.75 & 25.65 & 105.82 & 453.64 \\
$7: 3$ & 15.84 & 32.01 & 23.93 & 143.48 & 659.57 \\
$8: 2$ & 15.15 & 32.32 & 24.47 & 132.01 & 566.38 \\
$9: 1$ & 14.98 & 39.51 & 30.02 & 132.94 & 597.14 \\
\hline
\end{tabular}

\section{Results and Discussion of the DSC of the Composite Phase Change Materials}

The DSC of the Composite Phase Change Materials. We use capric acid and lauric acid to prepare phase change materials and use swelling vitrified beads as a kind of adsorption materials to make composite phase change materials. we use the mean of vacuum adsorption to prepare the composite phase change materials of different rates. The experimental results have been shown in figure $10-15$ and table 2 .

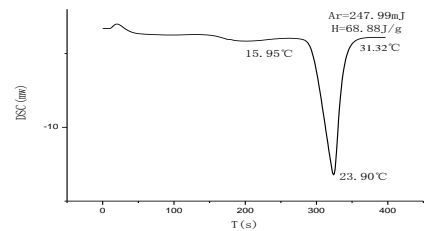

Fig.10 Absorb PCM 49\%

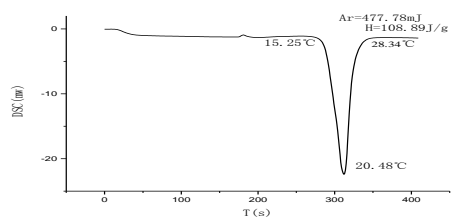

Fig.13 Absorb PCM 60\%

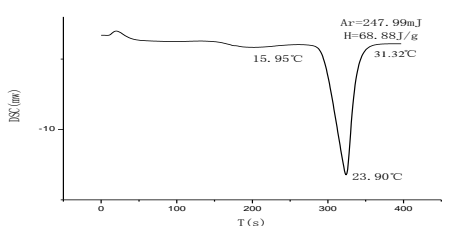

Fig.11 Absorb PCM 53\%

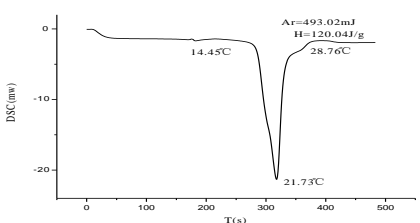

Fig.14 Absorb PCM 63.5\%

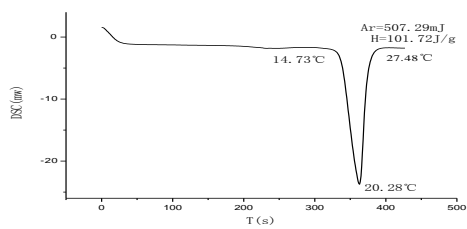

Fig. 12 Absorb PCM 57\%

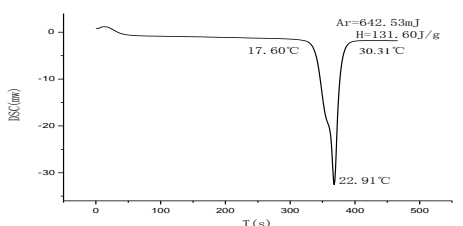

Fig.15 Absorb PCM 66\%

Results and Discussion. During the experiment, we found that the more increasing the amount of adsorption of the phase change material, the more difficult of adsorption by swelling vitrified beads and the time of the vacuum also increased. When the absorption rate is $66 \%$, the surface of the composite phase change material appeared the phenomenon of the leakage and the inner wall of the three-necked flask was wet. It showed that the phase change material has been attracted to the upper limit of the leakage. If the amount of phase change materials which is adsorbed is too much. It would have a negative impact on the environment if this composite phase change material was appeared.

As it can be seen from table 2. Along with the augment of amount of phase change materials which were adsorbed. Composite phase change material's temperature tends to be stable. Its phase change temperature is consistent with the PCM and its heat also increases with the increasing of amount of phase change materials. Therefore we can conclude to ensure composite phase change 
material as a whole is stable, it should be as much as adsorbed phase change material. It can be obtained a kind of composite phase change material of high heat to increase saving rate.

By calculating, adsorption rates of the phase change materials are respectively $49 \%, 53 \%, 57 \%$, $60 \%, 63.5 \%, 66 \%$. When the phase change material's content is $66 \%$, the composite phase change material occurs the phenomenon of the clear leakage of liquid when the temperature aboves the melting point of the phase change material. It is because the swelling vitrified beads' adsorption capacity is limited. There is a critical value, if the amount of adsorption beyond this critical value, the phase change material can not be completely adsorbed by the swelling vitrified beads. According to the experimental and the observation of the DSC test, when the adsorption rate reached $63.5 \%$, the phase transition temperature is $21.73^{\circ} \mathrm{C}$, the latent heat is $120.04 \mathrm{~J} / \mathrm{g}$, the endothermic peak area is $493.02 \mathrm{~mJ}$. At this point, the phase transition temperature is suitable for the living environment of the northern interior and it has a high latent heat. The composite phase change materials conform to actual requirement.

Tab.2 The characterization of the composite phase change materials

\begin{tabular}{cccccc}
\hline $\begin{array}{c}\text { The adsorption } \\
\text { rate }(\%)\end{array}$ & $\begin{array}{c}\text { The initial } \\
\text { temperatur } \\
\mathrm{e}\left({ }^{\circ} \mathrm{C}\right)\end{array}$ & $\begin{array}{c}\text { Final } \\
\text { temperatu } \\
\text { re }\left({ }^{\circ} \mathrm{C}\right)\end{array}$ & $\begin{array}{c}\text { Phase-transiti } \\
\text { on } \\
\text { temperature } \\
\left({ }^{\circ} \mathrm{C}\right)\end{array}$ & Heat $(\mathrm{J} / \mathrm{g})$ & $\begin{array}{c}\text { Endothermic } \\
\text { peak area }(\mathrm{mJ})\end{array}$ \\
\hline 49.0 & 15.95 & 31.32 & 23.90 & 68.88 & 247.99 \\
53.0 & 15.77 & 28.97 & 22.47 & 71.80 & 342.31 \\
57.0 & 14.73 & 27.48 & 20.28 & 101.72 & 507.29 \\
60.0 & 15.25 & 28.34 & 20.48 & 108.89 & 477.78 \\
63.5 & 14.45 & 28.76 & 21.73 & 120.04 & 493.02 \\
66.0 & 17.60 & 30.31 & 22.91 & 131.60 & 642.53 \\
\hline
\end{tabular}

\section{Micro-structure Analysis}

Figure 16 is the SEM image of swelling vitrified beads with respectively magnified 100 times and 300 times. Figure 17 is the SEM image of the composite phase change material (the absorption rate of phase change material is $63.5 \%$ ) with respectively magnified 200 times and 500 times.

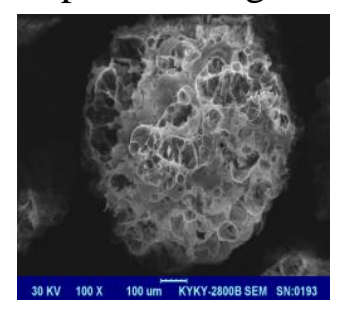

a

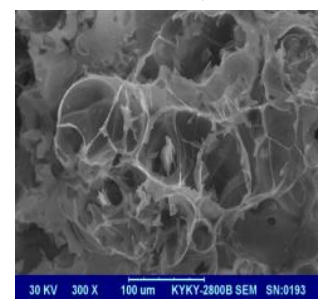

b

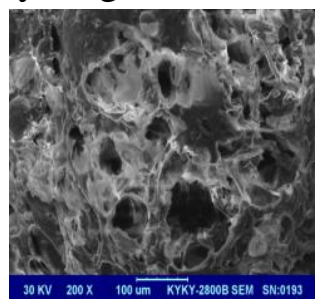

a

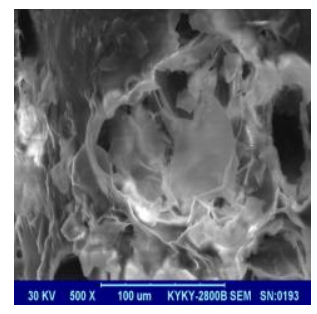

b

Fig .16 SEM image of the Vitrified microsphere

Fig .17 SEM of the Composite PCM

It can be analyzed from the figure 16, swelling vitrified beads have higher porosity factor, its pore structure is more evenly uniform and its aperture size falls in between 30-40 um and there is interconnected pore. Basically, they are opening pores connecting with the outside world. It creates the necessary condition for adsorption phase change materials. It can be analyzed from figure 17 and combined with macroscopic phase transition, when the adsorption was $63.5 \%$, it does not generate obvious liquid on the macro because of the Unique pore structure of the swelling vitrified beads. When the pore size is 5-10 um, the phase change material changes from the solid phase into the liquid phase. Because of the effect of capillary tension, it does not generate obvious liquid on the macro. In this paper, although the swelling vitrified beads as a kind adsorption carrier, its aperture size is large and it has a large of intercommunicating pores. But the mass ratio of the adsorbent material and the phase change material is reasonable. In the range of $63.5 \%$, the phase 
change material can be adsorbed to the inner wall of expandable holes of swelling vitrified beads. We can clearly see the phase change material of the inner wall of the swelling vitrified beads. It shows that expansive glass has good adsorption to absorb the phase change material by SEM images under the condition of vacuum. Because of the infiltration of the inner surface, the liquefied phase change material does not overflow from the hole. It is still a solid-solid composite phase change material. Finally we can conclude that the swelling vitrified beads can be used as a kind of adsorption carrier.

\section{Conclusion}

In this experiment, we adopt physical mixing method to prepare phase change materials of binary system. We prepare phase change materials of binary system in accordance with a certain proportion of the molten, according to the thermodynamic basis for the two-phase eutectic melting point theory and kinetic theory. We prepare compound phase change material by vacuum suction method, and then study a reasonable proportion for composite phase change materials.

(1)When CA : $\mathrm{LA}=7: 3$, phase change latent heat reaches the highest-143.48J/g, phase transition temperature is $23.93{ }^{\circ} \mathrm{C}$, endothermic peak area is $659.57 \mathrm{~mJ}$;

(2)In composite phase change energy storage material, the most suitable proportion of phase change materials and carrier is $1.8: 1$. At this time, phase transition temperature is $21.73^{\circ} \mathrm{C}$, phase change latent heat is $120.04 \mathrm{~J} / \mathrm{g}$, endothermic peak area is $493.02 \mathrm{~mJ}$;

(3)Through analysis of SEM test that phase change materials in the swelling vitrified beads, it shows that heat storage capacity of phase change energy storage material will improve in the porous substrate materials and its thermal performance is stable when the phase change material changes. Their combination is very good between phase change materials and porous substrate materials. As well as, heat transfer performance of the phase change materials gets improved due to the penetration of swelling vitrified beads. The results show that the porous matrix composite phase change material has a high heat storage capacity and good thermal stability.

\section{Acknowledgements}

This work was financially supported by the Jilin Science and Technology Foundation (20140307005S,20130204009SF).

\section{References}

[1]Feng Ma:Functional materials Vol.41(2010), p.180.

[2]Fang WU:Research on Binary Multiple Decanoic Acid-lauric Acid Phase Change Material (PCM)Vol.31(2009), p.134.

[3]Liguang Xiao: Journal of Jilin Institute of Architecture and Civil Engineering Vol.29(2012), p.35.

[4]Cheng SHEN:Research Progress of Phase Change Materials in Energy-efficient Buildings Vol.29(2015), p.100.

[5]Liguang Xiao:Study of the New Phase Change Composite Materials Vol.25(2008), p.7. 